\title{
El quinto sentido
}

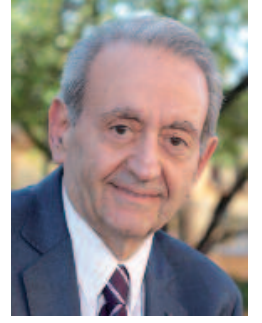

Juan José Vilata Corell

Catedrático de Dermatología y Venereología. Facultad de Medicina de Valencia. Universitat de València.
La dermatología es la disciplina que se ocupa del conocimiento de la piel humana sana, de las posibles enfermedades que primitiva o secundariamente la pueden afectar, de la preservación de los agentes nocivos externos, y de la recuperación de la normalidad cutánea. En la definición incluye las enfermedades de transmisión sexual, por ser muy frecuentes las manifestaciones cutáneas en estas entidades nosológicas, y la estética, como dos subespecialidades que engloban el espectro de la atención del dermatólogo actual.

La piel es un órgano con múltiples funciones, muy importantes todas y necesarias para la vida del individuo. La piel y el pelo tienen una función social trascendente y con un gran simbolismo para todas las culturas. La piel es lo que nos une y lo que nos separa a los individuos, se ha ensalzado en todas las artes, une y diferencia pueblos, se arraigan y desencadenan pasiones por ella, el contacto puede producir atracción o rechazo, se pinta, tatúa o se producen heridas rituales, todo ello para expresar estados de alegría o de angustia, desde la muerte hasta la vida, o para proteger de malos espíritus.

Con ello quiero hacer ver que el hecho de tener la piel tan a mano hace que la consideremos un objeto de todos, incluso la calificaría como «patrimonio de la humanidad», y que toda persona puede tratar de cambiarla o de reflejar en ella sus inquie- tudes y querer expresar, cual firmas de excepción, su marchamo personal en su propia piel o en la piel de otro individuo en ocasiones con dudosa justificación.

Pero, abandonemos el lento caminar de todas las culturas con la expresión de sus creencias en la piel y adentrémonos en la vorágine de acontecimientos científicos que ha supuesto que la dermatología en los últimos 50 años se haya posicionado gracias a la dermatopatología, la biología molecular, la genética y las técnicas de imagen como una de las disciplinas más avanzadas del mundo occidental.

Sin embargo, su desarrollo ha hecho que se engarce con muchas otras disciplinas médicas y quirúrgicas. Es un valor añadido. Asimismo, debido a los conocimientos actuales del dermatólogo por su experiencia clínica, por investigación básica o clínica, no se puede separar el diagnóstico y tratamiento de la prevención de la piel sana, de la recomendación de cosméticos y tratamientos estéticos. Este conjunto de competencias hace que no solo colabore con todas las especialidades afines que engloban la medicina interna, la urología, la ginecología, la cirugía plástica, la microbiología, la medicina preventiva... y así un sinfín de disciplinas. Nos ayudamos los unos a los otros y el beneficiado será siempre el paciente o el individuo sano que busca consejo y por ende lo recibe la sociedad en general. 


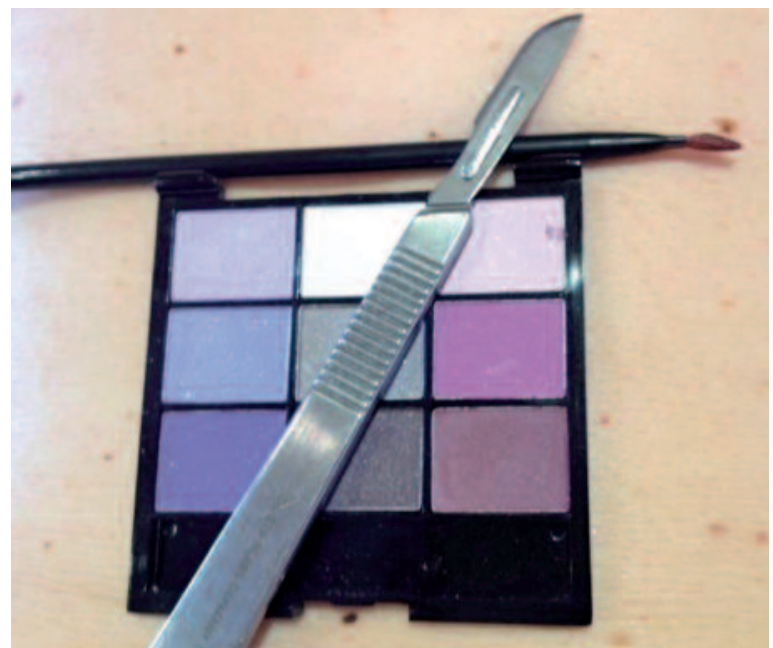

La piel: arte y ciencia.

En los últimos 40 años se han incrementado progresivamente las consultas en atención primaria por aspectos patológicos y estéticos de la piel, y en diversos estudios realizados en España se ha observado que del $8 \%$ al $20 \%$ de los que acuden al médico de atención primaria en la seguridad social solicitan atención dermatológica, de lo que se desprende que hay una gran preocupación del ciudadano por su piel y una alta demanda de problemas o consejos cutáneos.

No olvidemos que el dermatólogo también colabora con otras profesiones afines como farmacéuticos, biólogos y químicos, que muchos de ellos trabajan en empresas de prestigio de la industria cosmética y estética, para que en conjunto podamos conseguir los mejores productos para alcanzar distintos objetivos, como la prevención del daño solar y evitar el consiguiente envejecimiento de la piel, el cuidado de la piel eudérmica seca o seborreica, cuidados del cabello y otros estados no considerados patológicos susceptibles de ser tratados con cosméticos, cosmecéuticos y modernas tecnologías como los láseres, que en manos del dermatólogo dan una seguridad casi absoluta.

Se preguntará el lector, cómo el dermatólogo después de su formación de cuatro años puede mantenerse al día. Pues gracias a que los dermatólogos somos miembros de la Academia Española de Dermatología y Venereología (AEDV), la sociedad científica más antigua de España, en la que se imparte formación continua de una forma permanente, y gracias a los grupos de trabajo de las distintas subespecialidades, que son auténticos foros de estudio que contribuyen a la actualización científica del dermatólogo. La AEDV también se relaciona con las sociedades dermatológicas internacionales de mayor nivel científico y se añaden otros valores que contribuyen a que los dermatólogos españoles estemos al mismo nivel que la dermatología europea o americana. Llegan tiempos de cambios en la sociedad española, y nuestra AEDV implementará la gestión dirigida a la calidad, para que la sociedad española se beneficie todavía más.

He querido expresarme desde la dulce experiencia de la madurez para mostrar la evolución progresiva y positiva de los dermatólogos en los últimos años, de su capacidad de colaborar con especialidades médicas y profesionales afines, afrontando las nuevas líneas de investigación científicas con mente abierta y receptiva para volcar nuestros conocimientos a la sociedad española.

Y a modo de última reflexión sobre la piel, recordemos que es un sentido más, con cada vez mayores capacidades: un mecanismo fisiológico que permite percibir lo que está a nuestro alrededor, para mejorar nuestra supervivencia y nuestra calidad de vida. 